\title{
Efficacy of tiotropium and olodaterol combination therapy on dynamic lung hyperinflation evaluated by hyperventilation in COPD: an open-label, comparative before and after treatment study
}

This article was published in the following Dove Press journal:

International Journal of Chronic Obstructive Pulmonary Disease

\section{Shohei Kawachi ${ }^{1}$ \\ Keisaku Fujimoto ${ }^{2}$ \\ 'Department of Biomedical Laboratory Science, Graduate School of Medicine, Shinshu University, Nagano 390-862I, Japan; ${ }^{2}$ Department of Clinical Laboratory Sciences, Shinshu University School of Health Sciences, Matsumoto 390-8621, Japan}

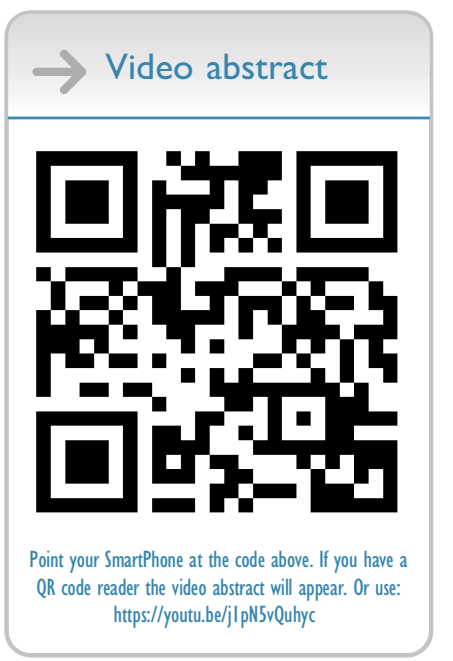

Correspondence: Keisaku Fujimoto Department of Clinical Laboratory Sciences, Shinshu University School of Health Sciences, 3-I-I, Asahi, Matsumoto 390-862I, Japan

Tel +8I 263372393

$\mathrm{Fax}+81263372393$

Email keisaku@shinshu-u.ac.jp
Background: Dynamic lung hyperinflation (DLH) following metronome-paced incremental hyperventilation (MPIH) was reported to be useful for assessment of pathophysiological impairment in patients with chronic obstructive pulmonary disease (COPD), and the effects of tiotropium and olodaterol on DLH following MPIH have not been reported.

Methods: Treatment consisted of administration of tiotropium/olodaterol $5 / 5 \mu \mathrm{g}$ inhalation solution $(2.5 / 2.5 \mu \mathrm{g}$ per actuation) using a soft-mist inhaler once a day. We compared outcomes before and after 8 weeks of treatment. The primary outcome was defined as a decrease in inspiratory capacity (IC) from rest by MPIH, which is an index of DLH. The secondary outcomes were COPD assessment test (CAT), forced expiratory volume in $1 \mathrm{~s}$ $\left(\mathrm{FEV}_{1}\right)$, and 6-min walking distance (6MWD). In addition, we investigated whether there were correlations between changes with treatment in $\mathrm{DLH}$ and $\mathrm{FEV}_{1}, 6 \mathrm{MWD}$, and dyspnea. Results: Thirty-three of the 38 registered patients completed this study. Most of these 33 patients had mild to moderate COPD. Decreasing IC by MPIH was significantly reduced by treatment for 8 weeks, with a mean change of about -0.11 to $-0.13 \mathrm{~mL}(P<0.05)$. In addition, CAT score, $\mathrm{FEV}_{1}$, and 6MWD improved with treatment $(P<0.05)$. There were no significant correlations between changes in $\mathrm{DLH}, \mathrm{FEV}_{1}, 6 \mathrm{MWD}$, or dyspnea with treatment.

Conclusions: The results of this study showed that the combination of tiotropium and olodaterol is effective for improvement of DLH following hyperventilation.

Keywords: bronchodilator agents, tiotropium, olodaterol, dynamic lung hyperinflation, hyperventilation

\section{Introduction}

Dynamic lung hyperinflation (DLH) is an important factor involved in dyspnea on exertion and exercise limitation in chronic obstructive pulmonary disease (COPD). ${ }^{1}$ Therefore, it is important to improve DLH by treatment. DLH involves hyperinflation of the lung, which progresses by hyperventilation with exertion. In patients with COPD, the decrease in lung elastic recoil pressure and narrowing of the peripheral bronchial lumen have been considered to induce lung hyperinflation. Therefore, exhalation may not be completed prior to the onset of the next breath, causing progressive hyperinflation. ${ }^{2}$ DLH refers to the variable increase in endexpiratory lung volume (EELV) above the relaxation volume of the respiratory 
system. ${ }^{3}$ As total lung capacity (TLC) remains essentially unchanged during exercise, changes in EELV during exercise can be reliably tracked by serial inspiratory capacity (IC) measurements. ${ }^{4}$

There is evidence that combined administration of a long-acting muscarinic antagonist (LAMA) and longacting $\beta 2$ agonist (LABA) in patients with COPD provides increases forced expiratory volume in $1 \mathrm{~s}\left(\mathrm{FEV}_{1}\right)$ and reduces symptoms compared to monotherapy. Therefore, combination therapy with LAMA and LABA is recommended in patients with more severe symptoms, especially those suffering from dyspnea and exercise limitation. ${ }^{5}$ Previous clinical trials have demonstrated the efficacy of combined treatment with tiotropium and olodaterol on $\mathrm{FEV}_{1}$, health-related quality of life, and exacerbation in patients with COPD. ${ }^{6,7,8}$ In addition, the MORACTO trial demonstrated improvements of IC at rest and during exercise associated with tiotropium and olodaterol treatment. ${ }^{9}$ However, the effects of tiotropium and olodaterol on DLH following metronome-paced incremental hyperventilation (MPIH) have not been reported. Gelb et al, reported that the non-invasive simplicity of hyperventilation provides a clinically useful screening surrogate for monitoring changes in IC following exercise. ${ }^{10}$ Then, we reported DLH following MPIH using a spirometer. DLH is dependent on the increase in respiration rate, and we measured the decrease in IC with stepwise increases in respiration rate (Figure 1). IC is significantly reduced in patients with COPD, resulting in DLH. Therefore, we showed that DLH following MPIH is useful for assessment of pathophysiological impairment in patients with COPD. ${ }^{11}$ Using this method, we investigated the effects of single and combined use of LAMA and LABA in DLH. ${ }^{12,13}$ However, the effects of tiotropium and olodaterol on DLH following MPIH have not been reported. This study was performed to elucidate the effects of combined treatment with tiotropium and olodaterol on DLH following MPIH in patients with COPD.

\section{Materials and methods}

\section{Subjects}

The study population consisted of patients with stable COPD who visited Shinshu University Hospital (Matsumoto, Nagano, Japan) or Shinsei Hospital (Obuse, Nagano, Japan) between March 1, 2017, and December 1, 2018. Diagnosis was made according to the Global Initiative for Chronic Obstructive Lung Disease (GOLD) criteria. ${ }^{5}$ Patients were diagnosed based on medical history and respiratory function characterized by clinical symptoms and irreversible airflow obstruction.

All patients suffered from smoking-related COPD without $\alpha_{1}$ antitrypsin deficiency, and those with a smoking history of $\geq 10$ pack-years, including current smokers, were selected for this study. In addition, as a substitute for LAMA and LABA during the washout period, patients whose symptoms responded to short-acting treatment were selected as eligible for inclusion. After receiving a thorough explanation of the study, patients who provided written consent were enrolled in the study. Patients with dysuria due to prostate hypertrophy, glaucoma, severe heart failure, symptom exacerbation and/or respiratory infection within 3 months, prior history of lung surgery, severe heart disease, or impairment or difficulty in walking due to motor or cognitive dysfunction were excluded. A history of exacerbation was defined as acute worsening of respiratory symptoms that resulted in additional therapy. ${ }^{5}$ Registration in this study was suspended for patients who declined to participate or withdrew their consent or if it was found after registration that the subject did not satisfy the eligibility criteria.

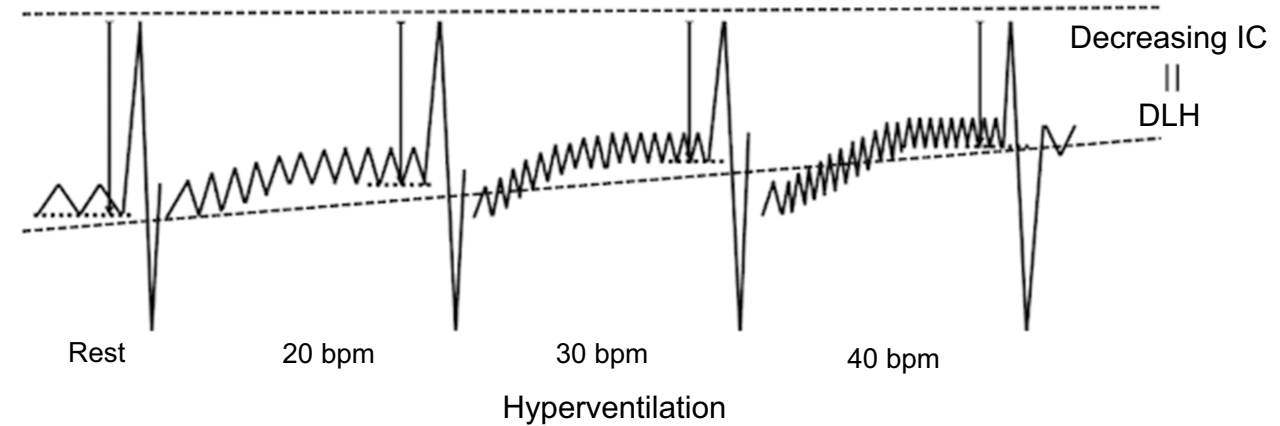

Figure I Method for measuring dynamic lung hyperinflation by hyperventilation. Abbreviations: IC, inspiratory capacity; bpm, breaths/min; DLH, dynamic lung hyperinflation. 


\section{Ethical considerations}

This study was conducted in accordance with the tenets of the Declaration of Helsinki, received approval from Shinshu University Medical Ethics Committee (approval number: 3654), and has been registered in the University Hospital Medical Information Network Clinical Trials Registry system (trial ID: UMIN000027521). Individual de-identified participant data for all outcomes were used in the analysis and shared on the University Hospital Medical Information Network Clinical Trials Registry system (UMIN). The data can be accessed by registering with UMIN, and then contacting the author to receive the appropriate URL. As the number of people that can view the data is limited, this requires approval from the author. The data have already been registered on UMIN, and there is no restriction on the period of publication. Documents related to other available study are research plan on the internet.

\section{Study design}

This study had an open-label, prospective, comparative before and after treatment design. Patients visiting the hospital for diagnosis and treatment of COPD who provided informed consent were included in the study. The combination of LAMA and LABA used consisted of Spiolto $^{\mathrm{TM}}$ and Respimat ${ }^{\circledR}$, respectively (Nippon Boehringer Ingelheim Co., Ltd., Tokyo, Japan), which contained $2.5 \mu \mathrm{g}$ of tiotropium and $2.5 \mu \mathrm{g}$ of olodaterol per puff, respectively. We set a washout period of 3 days before the baseline examination in patients who had already been prescribed LAMA, LABA, and/or inhaled corticosteroid (ICS) based on their half-lives. ${ }^{14,15}$ In an emergency during the washout period, short-acting treatment was used to respond to symptoms. Patients first underwent baseline examination after washout consisting of COPD questionnaire followed by lung function testing. Then, we performed DLH measurement by MPIH followed by 6 -min walking test (6MWT). Treatment was performed on the day after completion of the baseline examination, and consisted of administration of tiotropium/olodaterol $5 / 5 \mu \mathrm{g}$ inhalation solution $(2.5 / 2.5 \mu \mathrm{g}$ per actuation) using a soft-mist inhaler. Patients were instructed to inhale two puffs from the inhaler, once a day, in the morning. After 8 weeks, the same test was repeated for before and after comparison following inhalation as usual. The primary outcome was defined as a decrease in IC from rest by MPIH, which is an index of DLH. The secondary outcomes were the COPD assessment test (CAT), $\mathrm{FEV}_{1}$, and 6-min walking distance (6MWD). As in previous studies, we also investigated whether there were correlations between changes in DLH and exercise tolerance or dyspnea on exercise associated with treatment.

\section{Efficacy outcomes DLH}

In this study, DLH was measured using a spirometer (Fukuda Denshi Co., Ltd., Tokyo, Japan). The subjects regulated their breathing rate and timing in accordance with a light-emitting diode lamp for inspiration and expiration using a buzzer sound in place of a metronome. Each subject was asked to take several breaths at rest and then perform maximum inspiration followed by maximum expiration. Figure 2 shows the measurement of DLH based on MPIH using a spirometer. The resting IC and vital capacity (VC) was then measured. Next, the subjects breathed in synchronization with a pulsing sound and light for $30 \mathrm{~s}$ at a respiratory rate of 20 breaths/min (bpm). Finally, the subjects performed maximum inspiration. After a 1-2 mins pause, the respiratory rate was increased in steps to $30 \mathrm{bpm}$ for $30 \mathrm{~s}$ and then to $40 \mathrm{bpm}$ for $30 \mathrm{~s}$. At the end of each period of hyperventilation, the subjects performed maximum inspiration, and the IC was measured. The average of the valleys of three breaths just before maximum inspiration was set as the EELV, and the IC was measured from the EELV. IC
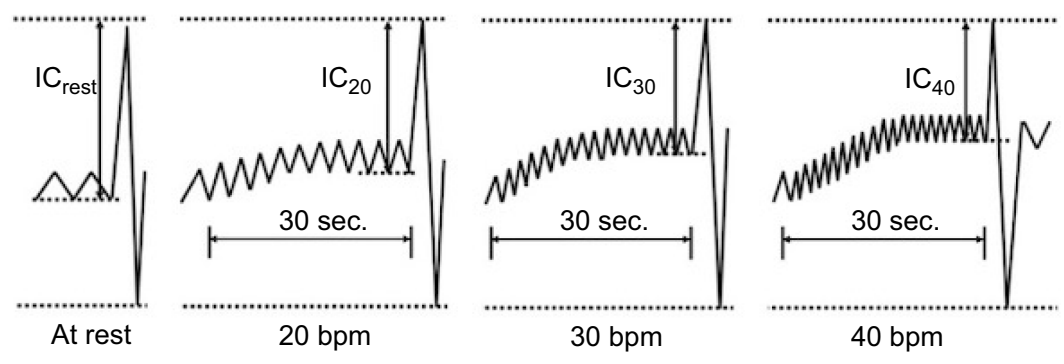

Figure 2 Details of dynamic lung hyperinflation measurement method using spirometer.

Abbreviations: IC, inspiratory capacity; bpm, breaths/min; IC rest IC at rest; IC 20 , IC at 20 bpm; IC 30 , IC at 30 bpm; IC 40 , IC at 40 bpm. 
measurement by each hyperventilation was repeated three times, and the machine automatically calculated the average. The ICs at rest and at hyperventilation rates of 20, 30, and 40 bpm were expressed as the $\mathrm{IC}_{\text {rest }}, \mathrm{IC}_{20}, \mathrm{IC}_{30}$, and $\mathrm{IC}_{40}$, respectively. DLH was evaluated from the decreases in $\mathrm{IC}$ from $\mathrm{IC}_{\text {rest }}$ to $\mathrm{IC}_{20}\left(-\mathrm{IC}_{20} ; \mathrm{IC}_{20}-\mathrm{IC}_{\text {rest }}\right)$, to $\mathrm{IC}_{30}\left(-\mathrm{IC}_{30} ; \mathrm{IC}_{30}-\mathrm{IC}_{\text {rest }}\right)$, and to $\mathrm{IC}_{40}\left(-\mathrm{IC}_{40} ; \mathrm{IC}_{40}-\mathrm{IC}_{\text {rest }}\right)$. The ratios of $-\mathrm{IC}_{20},-\mathrm{IC}_{30}$, and $-\mathrm{IC}_{40}$ to resting $\mathrm{IC}$ were expressed as $\Delta \mathrm{IC}_{20}, \Delta \mathrm{IC}_{30}$, and $\Delta \mathrm{IC}_{40}$, respectively.

\section{Questionnaire}

CAT was used to comprehensively evaluate the symptoms of COPD, and the Modified Medical Research Council dyspnea scale was used to evaluate subjective dyspnea.

\section{Lung function}

Spirometry, FRC lung volume, and lung diffusion capacity for carbon monoxide ( $\mathrm{DL}_{\mathrm{CO}}$ ) were measured using a spirometer (Chestac 8900; Nihon Kohden Co., Ltd., Tokyo, Japan). FRC and $\mathrm{DL}_{\mathrm{CO}}$ were evaluated only at the first examination. FRC was measured using a body box, after which the subject immediately inspired to TLC and expired maximally to $\mathrm{RV}$, allowing calculation of lung volume and RV/TLC. For predicted values of $\mathrm{FEV}_{1}$ and VC, Japanese local reference data developed by the Japanese Respiratory Society were adopted, ${ }^{16}$ and predicted values for $\mathrm{DL}_{\mathrm{CO}}$ and lung volumes (FRC, RV, and TLC) measured by body plethysmography were determined using the formulae of Nishida et al, ${ }^{17}$ and Boren et al, ${ }^{18}$, respectively. As Shinsei Hospital only has a spirometer, FRC and $\mathrm{DL}_{\mathrm{CO}}$ were not measured in patients at this hospital.

\section{6-Minute walking test}

The 6MWT was performed using a method that complied with the ATS Guidelines. ${ }^{19}$ Percutaneous oxygen saturation $\left(\mathrm{SpO}_{2}\right)$ and pulse rate were recorded using a wrist-worn pulse oximeter capable of automatic remote monitoring (WristOX ${ }_{2}{ }^{\mathrm{TM}}$, Model 3150; Philips Electronics Japan Co., Ltd., Tokyo, Japan). All patients were instructed to walk as far as possible over a 6-min period. The walking distance (m), $\mathrm{SpO}_{2}$, heart rate, and modified Borg scale (BS) rating before and immediately after the walking test were analyzed.

\section{Statistical analysis}

To compare the decreases in IC from $\mathrm{IC}_{\text {rest }}$ before and after treatment as indexes of DLH, we set conditions for statistical analyses with an examination power of
$80 \%$, an effect size of 0.4 , and significance probability of $5 \%$. The effect size was calculated in a previous study of the effects of bronchodilators on DLH by MPIH. ${ }^{13}$ The required sample size was calculated to be 38. The classification of COPD severity was based on airflow obstruction classification according to the GOLD criteria. ${ }^{5}$ The values in the text, tables, and figures are expressed as means \pm SEM. Wilcoxon's signed rank test was used for comparison of each outcome before and after treatment. Spearman's rank correlation coefficient was used for a single regression analysis between IC change due to treatment and $\mathrm{FEV}_{1}, 6 \mathrm{MWD}$, or BS change. In all analyses, $P<0.05$ was taken to indicate statistical significance. SPSS ver. 22 software was used for statistical analyses (SPS Inc., Chicago, IL).

\section{Results}

Five of the 38 registered patients dropped out of the study for hospitalization due to gastrointestinal disorder, discontinuation of hospital visits for unknown reasons, refusal to undergo examination after treatment, hospitalization due to exacerbation of respiratory diseases, and not meeting the criteria of COPD after registration into the study in one patient each. The results were not trough values, as the after treatment examination was conducted following inhalation as usual.

\section{Characteristics of patients and comparison of lung functions before and after treatment}

Table 1 shows the basic physical findings, smoking history, medication history, and the results before and after treatment for each lung function along with the questionnaire responses. The study population included patients with mild to severe COPD as determined by the classification of airflow limitation severity using $\% \mathrm{FEV}_{1},{ }^{5}$ with $60 \%$ of all subjects showing moderate disease status. $\mathrm{FEV}_{1}, \% \mathrm{FEV}_{1}$, and $\mathrm{FEV}_{1} / \mathrm{FVC}$ (forced vital capacity) ratio were significantly higher after treatment compared with before treatment (mean differences: $\mathrm{FEV}_{1}, 161 \pm 4$ $\mathrm{mL} ; \% \mathrm{FEV}_{1}, 5.4 \pm 1.4 \% ; \mathrm{FEV}_{1} / \mathrm{FVC}, 1.7 \pm 0.5 \%$ ), while CAT was lower after treatment (mean differences: CAT, $-2.1 \pm 0.8, \mathrm{MRC},-0.2 \pm 0.2$ ). 
Table I Characteristics of patients and comparison of lung function before and after treatment

\begin{tabular}{|c|c|c|}
\hline & Before & After \\
\hline$n$ & 33 & 33 \\
\hline Age, years & $76.2 \pm 1.2$ & \\
\hline Sex (male/female) & $32 / 1$ & $32 / 1$ \\
\hline Smoking history, pack $\times$ year & $53.3 \pm 5.8$ & \\
\hline Past smoker, n & 30 & \\
\hline Current smoker, $\mathrm{n}$ & 3 & \\
\hline $\mathrm{BMI}, \mathrm{kg} / \mathrm{m}^{2}$ & $22.7 \pm 0.4$ & \\
\hline CAT & $13.7 \pm 1.4$ & $10.8 \pm 1.2^{*}$ \\
\hline $\mathrm{mMRC}$ & $1.3 \pm 0.2$ & $1.0 \pm 0.2$ \\
\hline$\% \vee C, \%$ & $101.1 \pm 2.8$ & $105.1 \pm 2.2^{*}$ \\
\hline IC, L & $2.32 \pm 0.09$ & $2.32 \pm 0.06$ \\
\hline $\mathrm{FEV}_{1}, \mathrm{~L}$ & $1.58 \pm 0.10$ & $1.67 \pm 0.08 * *$ \\
\hline $\mathrm{FEV}_{1}, \%$ & $61.1 \pm 3.2$ & $63.9 \pm 2.6 * *$ \\
\hline $\mathrm{FEV}_{1} / \mathrm{FVC}, \%$ & $51.4 \pm 1.9$ & $51.6 \pm 1.8 * *$ \\
\hline$\% \mathrm{FRC}, \%$ & $99.7 \pm 3.9$ & \\
\hline$\% \mathrm{RV}, \%$ & $158.8 \pm 8.3$ & \\
\hline$\% T L C, \%$ & $125.6 \pm 3.4$ & \\
\hline RV/TLC, \% & $42.4 \pm 1.8$ & \\
\hline$\% D L C O, \%$ & $67.4 \pm 3.5$ & \\
\hline GOLD stage $(I, 2,3,4)$ & $4 / 21 / 7 / 1$ & \\
\hline \multicolumn{3}{|l|}{$\begin{array}{l}\text { Treatment with inhaled agents at } \\
\text { before including study }\end{array}$} \\
\hline No drug, $\mathrm{n}$ & 5 & \\
\hline LAMA, $n$ & 13 & \\
\hline LABA, $n$ & 2 & \\
\hline LAMA+LABA, $n$ & 4 & \\
\hline$L A B A+I C S, n$ & 2 & \\
\hline LAMA \pm LABA $\pm I C S, n$ & 7 & \\
\hline
\end{tabular}

Notes: Values represent mean \pm standard error of the mean; ${ }^{*} p<0.05$ and ${ }^{* *} p<0.01$ vs before treatment.

Abbreviations: BMI, body mass index; CAT, COPD assessment test; mMRC, Modified Medical Research Council dyspnea scale, VC, vital capacity; IC, inspiratory capacity; $F E V_{1}$, forced expiratory volume in I s; FVC, forced vital capacity; FRC, functional residual capacity; RV, residual volume; TLC, total lung capacity; DLCO, lung-diffusion capacity for carbon monoxide; LAMA, long-acting muscarinic antagonist; LABA, long-acting beta 2 agonist; ICS, inhaled corticosteroid.

\section{Comparison of DLH following MPIH and 6MWT before and after treatment}

Table 2 shows the results of comparing DLH by MPIH and exercise tolerance before and after treatment. $-\mathrm{IC}_{20},-\mathrm{IC}_{30}$, and $-\mathrm{IC}_{40}$ were significantly decreased after treatment (mean differences: $-\mathrm{IC}_{20},-0.12 \pm 0.06 \mathrm{~L} ;-\mathrm{IC}_{30},-0.11$ $\pm 0.05 \mathrm{~L} ;-\mathrm{IC}_{40},-0.13 \pm 0.06 \mathrm{~L}$ ) (Figure 3 ). $\mathrm{IC}_{20}, \mathrm{IC}_{30}$, and
$\mathrm{IC}_{40}$ were significantly increased after treatment (mean differences: $\mathrm{IC}_{\text {rest }}, 0.04 \pm 0.06 \mathrm{~L} ; \mathrm{IC}_{20}, 0.15 \pm 0.06 \mathrm{~L} ; \mathrm{IC}_{30}$, $0.15 \pm 0.04 \mathrm{~L} ; \mathrm{IC}_{40}, 0.17 \pm 0.05 \mathrm{~L}$ ). In addition, $\Delta \mathrm{IC}$ was significantly decreased after treatment. The $6 \mathrm{MWD}$ was significantly increased after treatment compared with the

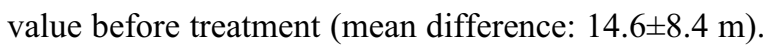

\section{Correlation of changes in DLH, FEV , exercise tolerance, and dyspnea with treatment}

Table 3 shows the correlations between change in DLH after treatment and the changes in $\mathrm{FEV}_{1}, 6 \mathrm{MWD}$, and maximum BS. There were no significant correlations between changes in $\mathrm{IC}, \mathrm{FEV}_{1}, 6 \mathrm{MWD}$, or $\mathrm{BS}_{\max }$ with treatment. The scatter plot in Figure 4 shows the correlations of changes in values with treatment between $6 \mathrm{MWD}$ and $\mathrm{FEV}_{1}, \mathrm{IC}_{40}$, or $-\mathrm{IC}_{40}$ and between $-\mathrm{IC}_{40}$ and $\mathrm{FEV}_{1}$.

Table 2 Comparison of dynamic lung hyperinflation following hyperventilation and 6-min walking test (6MWT) before and after treatment

\begin{tabular}{|c|c|c|}
\hline & Before & After \\
\hline $\mathrm{n}$ & 33 & 33 \\
\hline$I C_{\text {rest }}, \mathrm{L}$ & $2.39 \pm 0.08$ & $2.42 \pm 0.09$ \\
\hline $\mathrm{IC}_{20}, \mathrm{~L}$ & $2.25 \pm 0.09$ & $2.4 I \pm 0.09 *$ \\
\hline $\mathrm{IC}_{30}, \mathrm{~L}$ & $2.12 \pm 0.09$ & $2.27 \pm 0.09 * *$ \\
\hline$I_{40}, \mathrm{~L}$ & $1.99 \pm 0.10$ & $2.15 \pm 0.10 * *$ \\
\hline$-\mathrm{IC}_{20}, \mathrm{~L}$ & $-0.13 \pm 0.05$ & $-0.02 \pm 0.05 *$ \\
\hline$-\mathrm{IC}_{30}, \mathrm{~L}$ & $-0.27 \pm 0.05 \mathrm{tt}$ & $-0.16 \pm 0.06 * \dagger$ \\
\hline$-\mathrm{IC}_{40}, \mathrm{~L}$ & $-0.40 \pm 0.06 \mathrm{tt}^{\mathrm{t}}$ & $-0.27 \pm 0.06 * \dagger$ \\
\hline$\Delta \mathrm{IC}_{20}, \%$ & $-5.6 \pm 2.2$ & $0.5 \pm 2.5 *$ \\
\hline$\Delta \mathrm{I} \mathrm{C}_{30}, \%$ & $-11.6 \pm 2.3^{t \dagger}$ & $-5.5 \pm 2.8 * \dagger$ \\
\hline$\Delta \mathrm{IC}_{40}, \%$ & $-16.9 \pm 2.7^{t \dagger}$ & $-10.8 \pm 2.7 * * t \dagger$ \\
\hline 6MWD, m & $460.2 \pm 19.4$ & $477.1 \pm 18.4 *$ \\
\hline Pre $\mathrm{SpO}_{2}, \%$ & $95.3 \pm 0.3$ & $95.2 \pm 0.4$ \\
\hline Lowest $\mathrm{SpO}_{2}, \%$ & $87.3 \pm 0.9$ & $87.9 \pm 0.9$ \\
\hline $\mathrm{PR}_{\min }, \mathrm{bpm}$ & $73.4 \pm 2.3$ & $72.4 \pm 2.6$ \\
\hline $\mathrm{PR}_{\max }, \mathrm{bpm}$ & $115.0 \pm 2.4$ & $113.5 \pm 3.1$ \\
\hline $\mathrm{BS}_{\min }$ & $0.4 \pm 0.2$ & $0.3 \pm 0.2$ \\
\hline $\mathrm{BS}_{\max }$ & $5.2 \pm 0.5$ & $4.6 \pm 0.4$ \\
\hline
\end{tabular}

Notes: Values represent mean \pm standard error of the mean; ${ }^{*} p<0.05$ and ${ }^{*} p<0.01$ vs before treatment; ${ }^{\dagger} p<0.05$ and ${ }^{{ }^{\dagger}} p<0.0 \mathrm{I}$ vs $-\mathrm{IC}_{20}$ or $\Delta \mathrm{IC}_{20}$.

Abbreviations: IC, inspiratory capacity; bpm, breaths/min; IC rest, IC at rest; $I C_{20}$, IC at 20 bpm; $-\mathrm{IC}_{20}$, decrease in $\mathrm{IC}$ from $\mathrm{IC}_{\text {rest }}$ to $\mathrm{IC}_{20} ; \Delta \mathrm{IC}$, change in IC from IC rest to $I C_{20} ; I C_{30}, I C$ at $30 \mathrm{bpm} ;-\mathrm{IC}_{30}$, decrease in IC from IC rest to $I C_{30} ; \Delta C_{30}$, change in IC from IC $\mathrm{C}_{\text {rest }}$ to IC $\mathrm{IC}_{30} ; \mathrm{IC} \mathrm{C}_{40}, I \mathrm{IC}$ at $40 \mathrm{bpm} ;-\mathrm{IC}_{40}$, decrease in IC from IC rest to IC $\mathrm{C}_{40} ; \Delta \mathrm{IC}$, change in IC from $\mathrm{IC}_{\text {rest }}$ to $\mathrm{IC}_{40}$; $6 \mathrm{MWD}$, 6-min walking distance; $\mathrm{SpO}_{2}$, percutaneous oxygen saturation; $\mathrm{PR}_{\min }$, minimum pulse rate; $\mathrm{PR}_{\max }$, maximum pulse rate; $\mathrm{BS}_{\min }$, minimum modified Borg scale; $\mathrm{BS}_{\max }$, maximum modified Borg scale. 


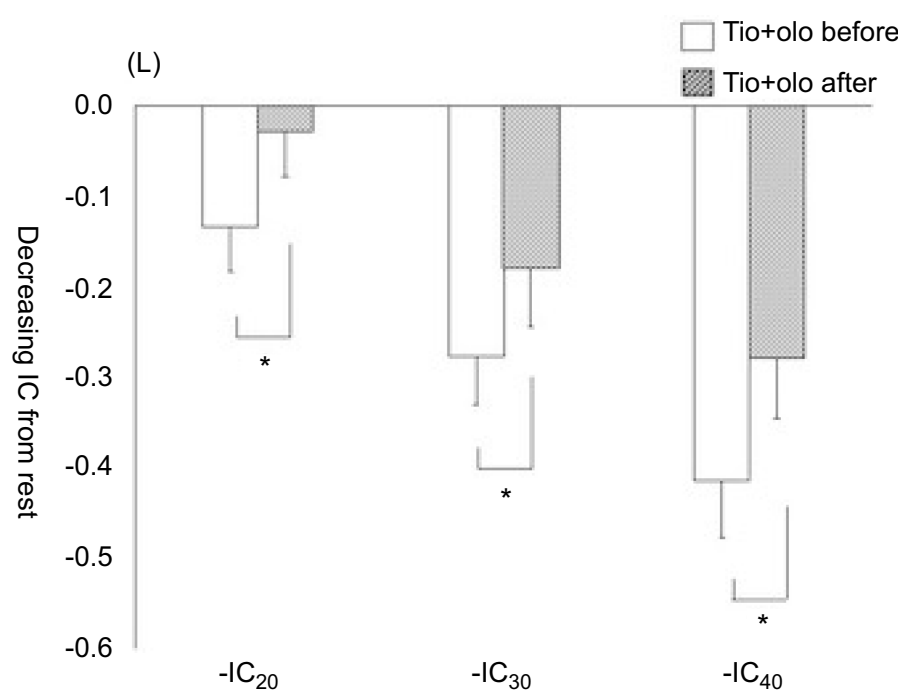

Figure 3 Comparison of dynamic lung hyperinflation following hyperventilation before and after treatment. $* P<0.05$ vs before combined treatment with tiotropium and olodaterol.

Abbreviations: Tio, Tiotropium; Olo, Olodaterol; IC, inspiratory capacity; bpm, breaths/min; IC rest $I C$ at rest; $-I C_{20}$, decrease in IC from IC rest to IC at 20 bpm; $-I C_{30}$, decrease in IC from $I C_{\text {rest }}$ to $I C$ at $30 \mathrm{bpm} ;-\mathrm{IC}_{40}$, decrease in IC from IC

\section{Discussion}

The present study was performed to elucidate the effects of combined treatment with tiotropium and olodaterol on DLH following MPIH. Thirty-three patients completed the study and five dropped out. Most of the 33 patients had mild to moderate COPD. $-\mathrm{IC}$ and $\triangle \mathrm{IC}$ decreased significantly and IC after each hyperventilation increased

Table 3 Correlation of changes in DLH, FEV , exercise tolerance, and dyspnea with treatment

\begin{tabular}{|l|l|l|l|}
\hline & FEV (L) & 6MWD (m) & BS $_{\max }$ \\
\hline $\mathrm{IC}_{\text {rest }}$ & 0.30 & 0.25 & 0.28 \\
$\mathrm{IC}_{20}$ & 0.06 & 0.05 & 0.06 \\
$\mathrm{IC}_{30}$ & 0.22 & 0.15 & 0.18 \\
$\mathrm{IC}$ & 0.13 & 0.18 & 0.06 \\
$-\mathrm{IC}$ & -0.23 & -0.20 & -0.17 \\
$-\mathrm{IC}_{30}$ & -0.06 & -0.14 & -0.13 \\
$-\mathrm{IC}$ & -0.17 & -0.12 & -0.14 \\
$\Delta \mathrm{IC}_{20}$ & -0.24 & -0.18 & -0.09 \\
$\Delta \mathrm{IC}_{30}$ & $-0.0 \mathrm{I}$ & -0.05 & -0.10 \\
$\Delta \mathrm{IC}_{40}$ & -0.03 & -0.02 & -0.17 \\
\hline
\end{tabular}

Notes: Values represent the means. The value of change associated with treatment was calculated as the post-value minus the pre-value.

Abbreviations: IC, inspiratory capacity; $I C_{\text {rest }}$, IC at rest; $I C_{20}, I C$ at $20 \mathrm{bpm}$; $I C_{20}$, decrease in IC from IC $C_{\text {rest }}$ to $I C_{20} ; \Delta I C_{20}$, change in IC from IC rest to IC $C_{20} ; I_{30}$, $\mathrm{IC}$ at $30 \mathrm{bpm} ;-\mathrm{IC}_{30}$, decrease in IC from $\mathrm{IC}_{\text {rest }}$ to $\mathrm{IC}_{30} ; \Delta \mathrm{IC}_{30}$, change in IC from $I C_{\text {rest }}$ to $I C_{30} ; I C_{40}$, IC at $40 \mathrm{bpm} ;-\mathrm{IC}_{40}$, decrease in IC from IC rest to IC $\mathrm{C}_{40} ; \Delta \mathrm{IC}_{40}$, change in IC from $I C_{\text {rest }}$ to $I C_{40}$. FEV , forced expiratory volume in I s; 6MWD, 6min walking distance; $\mathrm{BS}_{\max }$, maximum modified Borg scale. after treatment. In addition, lung functions, subjective symptoms, and exercise tolerance improved significantly with treatment for 8 weeks. There were no correlations between the changes in DLH and exercise tolerance, $\mathrm{FEV}_{1}$, or dyspnea. The results of this study revealed the effects of combined treatment with tiotropium and olodaterol on DLH following MPIH.

\section{Dynamic lung hyperinflation}

Previous studies demonstrated improvements in DLH using combinations of LAMA and LABA for DLH evaluated by MPIH methods and exercise loading. In a previous study using MPIH, the treatment groups receiving tiotropium/indacaterol $(5 / 150 \mu \mathrm{g})$, showed significant increases in $\mathrm{IC}_{20}, \mathrm{IC}_{30}$, and $\mathrm{IC}_{40}$ from resting $\mathrm{IC}$ of 0.10 , 0.15 , and $0.19 \mathrm{~L}$ in, respectively. ${ }^{13}$ The results of the present study were similar to those reported previously as olodaterol and indacaterol have similar efficacy in patients with COPD. ${ }^{20}$ However, we newly elucidated the effects of combined treatment with tiotropium and olodaterol on DLH following MPIH. As IC measurements were substituted for EELV, ${ }^{10}$ the changes in IC were due to the improvement of EELV. The DLH associated with increased EELV was improved by the increase in the exhalation flow rate by LAMA. ${ }^{21}$ Fujimoto et al, reported that EELV and IC were improved by bronchodilators based on measurements by MPIH. ${ }^{22}$ Therefore, improvement of DLH was suspected to have been due to increased expiratory flow by tiotropium and olodaterol in the present study. 

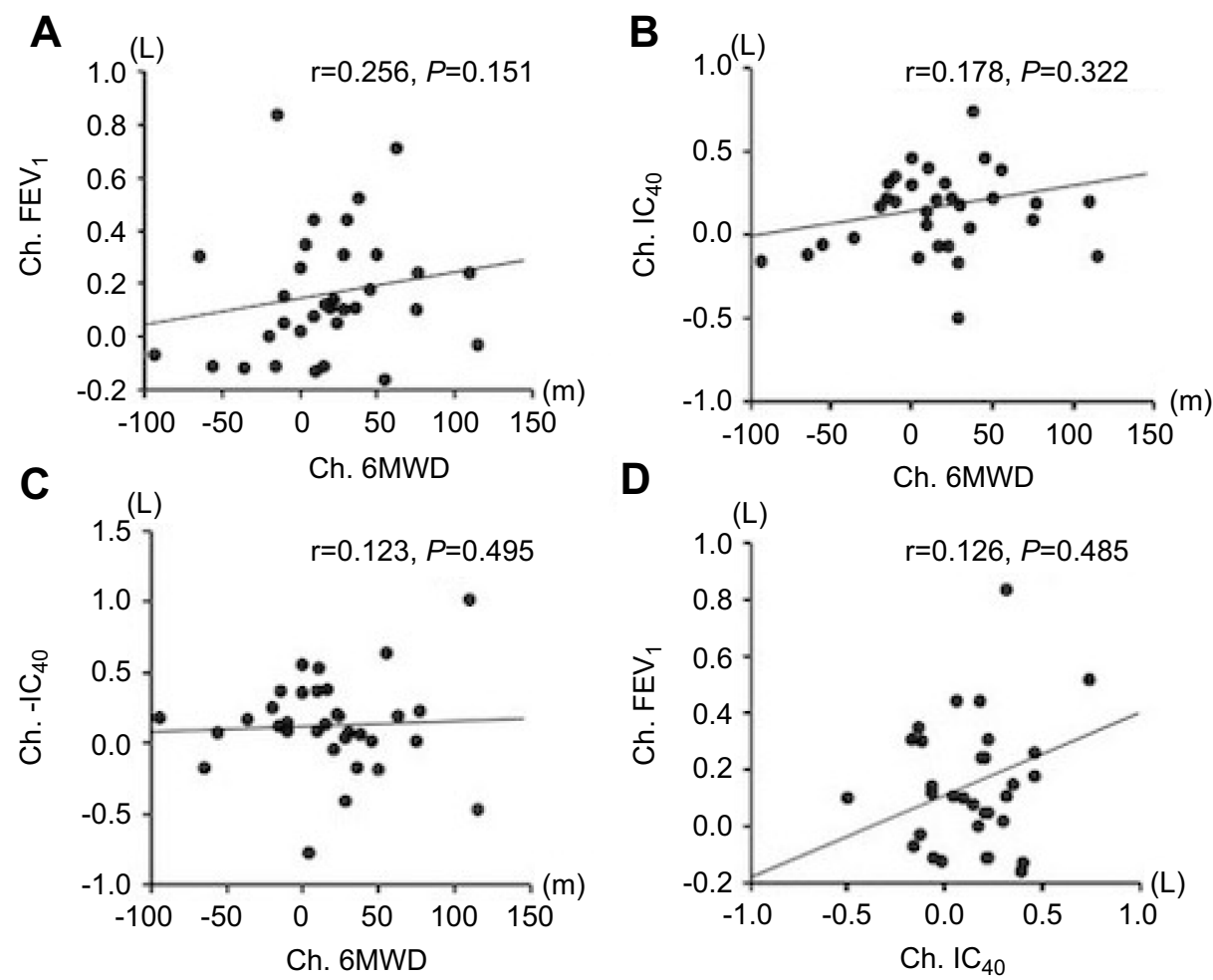

Figure 4 Correlations of changes in value associated with treatment between $6 \mathrm{MWD}$ and $\mathrm{FEV},(\mathbf{A}), \mathrm{IC}_{40}(\mathbf{B})$ or $-\mathrm{IC}_{40}(\mathbf{C})$ and between IC 40 and $\mathrm{FEV}\left(\mathrm{D}_{\mathrm{I}}\right)$. IC 40 , inspiratory capacity (IC) following 30-s hyperventilation at 40 breaths/min; $-I_{40}$, change in IC at rest to $I C_{40}$. The value of change associated with treatment was calculated as the postvalue minus the pre-value.

Abbreviations: $\mathrm{Ch}$, change in value by treatment; $\mathrm{FEV}_{\mathrm{I}}$, forced expiratory volume in I s; $6 \mathrm{MWD}$, 6-min walking distance; IC, inspiratory capacity; IC 40 , IC at 40 breaths/ min; $-I_{40}$, decrease in IC from IC at rest to $I C_{40}$.

In a study using exercise loading, O’Donnell et al, compared a combination of tiotropium and olodaterol $(2.5 / 5$ and $5 / 5 \mu \mathrm{g})$ with placebo or each agent administered alone as monotherapy. ${ }^{9}$ They measured periodical IC during exercise loading and IC decrease during exercise to evaluate DLH, and reported that resting IC increased significantly by $0.245 \mathrm{~L}$ after treatment compared to placebo. Furthermore, IC during exercise increased by about $0.1-0.15 \mathrm{~L}$ after treatment compared to each monotherapy. In the present study, however, the resting IC was increased by $0.04 \pm 0.06 \mathrm{~L}$, and IC by MPIH showed a mean increase of $0.17 \pm 0.05 \mathrm{~L}$ after treatment. In contrast to the previous study, only the resting IC did not show a significant improvement in the present study. Resting IC did not improve in a study of the effects of combined LAMA and LABA treatment in the study of Fujimoto et $\mathrm{al}^{13}$, but improvement was observed in another study by Ichinose et $\mathrm{al}^{23}$. Further studies of the effects on resting IC are required because the results were not consistent with previous studies of bronchodilators in Japanese subjects with the same characteristics.

\section{Lung function}

Previous studies have mainly reported the effects of combined treatment with tiotropium and olodaterol on lung function and subjective symptoms. Beeh et al, compared the effects between five groups, ie, tiotropium/olodaterol combination $(2.5 / 5$ and $5 / 5 \mu \mathrm{g})$, each monotherapy, and placebo. $^{7}$ They reported that the group receiving combined tiotropium/olodaterol treatment showed significantly improved $\mathrm{FEV}_{1}$ compared to the other groups. In the present study, the combination treatment with tiotropium and olodaterol showed improvements in subjective symptoms and $\mathrm{FEV}_{1}$, consistent with previous studies. However, these improvements were milder in the present study compared with previous reports. For example, Beeh et al, reported that Peak $\mathrm{P}_{0-3} \mathrm{FEV}_{1}$ was increased by $0.411 \mathrm{~L}$ compared to baseline by 6 weeks of combined treatment with tiotropium/olodaterol $(5 / 5 \mu \mathrm{g}){ }^{7}$ while an improvement of $0.161 \pm 0.004 \mathrm{~L}$ compared to baseline was observed after 8 weeks in the present study. Dave et al, reported a transition dyspnea index of 1.67-1.85 as a subjective symptom compared to baseline, representing an improvement of $>1$ in meaningful Minimal Clinical Important 
Difference (MCID) for dyspnea by treatment with tiotropium/olodaterol $(5 / 5 \mu \mathrm{g}),{ }^{24}$ while CAT showed improvement of $2.1 \pm 0.8$ compared to baseline, representing an improvement of $<3$ in MCID of CAT in the present study. Therefore, improvements in subjective symptoms and lung function were milder in the present study compared to previous reports. This was probably because the subjects in the present study were older than those in these previous studies. Tashkin et al, reported that advanced age was one of the baseline characteristics associated with poor response to bronchodilators in the UPLIFT study, which investigated the long-term effects of tiotropium for mild to moderate disease. ${ }^{25}$ While the average age of subjects in the previous clinical studies of tiotropium and olodaterol was 60 years, the subjects in the present study had an average age of 70 years. ${ }^{6,9}$ In addition, the mean age of subjects in a study of the same treatment regimen in Japanese subjects by Ichinose et al, was 72 years. $^{23}$ Ichinose et al, reported that $\mathrm{FEV}_{1}$ showed mild improvement from a baseline of $1.228-1.275 \mathrm{~L}$ after the same treatment as applied in the present study. Therefore, it was considered that the mild improvements of subjective symptoms and lung function in the present study were because of the advanced age of the subjects.

\section{Exercise tolerance}

Improvement of exercise tolerance was also observed in the present study, because 6MWD showed a significant increase after treatment. However, 6MWD showed an improvement of $<25-30 \mathrm{~m}$ in MCID of 6MWD in the present study. ${ }^{26}$ This was considered to have been due to the milder severity of disease in our patients. O'Donnell et al, reported that LAMA and LABA maintenance therapy in patients with COPD provide sustained lung volume reduction as a result of improved tidal expiratory flow rates and lung emptying, with reduced resting and exercise lung hyperinflation, and a delay in the mechanical limitation to ventilation, with consequent alleviation of exertional dyspnea and exercise capacity. ${ }^{21}$ In addition, combined tiotropium and olodaterol treatment were reported to affect exercise capacity. ${ }^{9}$ Therefore, the reduction in DLH was considered to have improved exercise tolerance in the present study. However, Ichinose et al, reported improvement in a subgroup with only severe COPD in a study with administration of the same treatment regimen in Japanese subjects. ${ }^{23}$ Although Ichinose demonstrated improvements only in severe COPD, the patients in the present study had mild to moderate
COPD. Several studies indicated that exercise capacity is improved in the subgroup with more severe COPD, ${ }^{23,27}$ while the results of the present study in patients with mild to moderate COPD were consistent with similar studies of tiotropium/olodaterol in patients with less severe disease. Ferguson et al, reported greater improvements compared to baseline after 24 weeks of tiotropium/olodaterol combination treatment in the subgroup with less severe COPD. ${ }^{28}$ Therefore, further studies are required to examine the improvement of exercise capacity in relation to severity, and the results reported to date have been inconsistent.

\section{Correlations of changes in DLH, FEV exercise tolerance, and dyspnea with} treatment

There were no correlations between changes associated with treatment in DLH and 6MWD or maximum BS. The results of the present study were different from those reported by O'Donnell et $\mathrm{al}^{21}$, which was probably due to differences in the methods used for evaluation of DLH between the two studies. O'Donnell et al, reported correlations between changes in DLH, exercise tolerance, and dyspnea during exercise after tiotropium monotherapy in a randomized controlled trial. In this previous study, DLH was evaluated based on the decrease in IC during exercise loading or just after exercise. On the other hand, hyperventilation and spirometer were used to evaluate DLH in the present study. It is unclear whether DLH induced by exercise loading is equivalent to DLH induced by $\mathrm{MPIH}$. We are currently engaged in experiments to determine whether DLH determined by exercise loading and DLH determined by MPIH are comparable, and plan to report our findings in the near future.

\section{Limitations}

The present study had several limitations. First, this was a pre- and post-treatment comparative study, and there was no control group. Comparison with placebo or conventional treatment was not performed. Therefore, it is possible that various confounding factors may have affected the results. Second, most of the patients had moderate disease status, and the effects on DLH may have been underestimated. As previous clinical trials examined combination therapy mainly in patients with mild to severe disease, ${ }^{6,9}$ the results of the present study may have been different if the disease status in the majority of our patients had been moderate to severe. Third, the study may have been underpowered 
because five patients dropped out. However, there was a significant difference in the main outcome in the 33 patients included in the analysis, and post hoc analysis demonstrated that the statistical power was $\geq 80 \%$. Fourth, the washout period used in the present study was short. The recommended washout period is five times the half-life. ${ }^{29}$ As the half-lives of tiotropium, olodaterol, and ICS are 25, 7.5, and $14.4 \mathrm{hrs}$, respectively, the washout period for tiotropium was too short in the present study.

\section{Conclusion}

In conclusion, the results of this study indicated that the combination of tiotropium and olodaterol is effective for improvement of DLH following hyperventilation. In addition, this study showed a difference in the response of DLH due to exercise loading to treatment compared to previous studies. Therefore, further studies are required to examine the differences in responses between exercise loading and hyperventilation.

\section{Acknowledgments}

The authors wish to thank Dr. Mineko Ohira (Shinsei Hospital \& Higashi Nagano Hospital) and Dr. Takashi Ichiyama (Shinshu University Hospital) for their help in registration of subjects for this study. This work was supported by the Nihon Rehabilitation Shinkokai Foundation (Koganei, Tokyo, Japan).

\section{Disclosure}

The authors received financial support from Nihon rehabilitation Shinkokai Foundation, a general incorporated foundation (Koganei, Tokyo, Japan) for this study. Keisaku Fujimoto reports grants from Murata Manufacturing Co., Ltd., Seiko Epson Corporation, Denso Corporation, Kanazawa Murata Manufacturing Co., and Koganei Corporation. He also received personal fees from Japan Association for the Advancement of Medical Equipment, Astellas Pharma Inc., AstraZeneca Co., Ltd., Fukuda Denshi Co., Ltd., Fukuda Lifetec Co., Ltd., GlaxoSmithKline Co., Ltd., Japan Respiratory Society, Kyorin Pharmaceutical Co., Ltd., MeijiSeika Pharma Co., Ltd., Otsuka Pharmaceutical Co., Ltd., Teijin Home Healthcare Limited, and Teijin Pharma Limited. He further received grants and personal fees from MSD Co., Ltd., Nippon Boehringer Ingelheim Co., Ltd. and Novartis Pharma Co., Ltd., outside the submitted work. The authors report no other conflicts of interest in this work.

\section{References}

1. O'Donnell DE, Revill SM, Webb KA. Dynamic hyperinflation and exercise intolerance in chronic obstructive pulmonary disease. Am J Respir Crit Care Med. 2001;164:770-777. doi:10.1164/ ajrccm.164.5.2012122

2. O'Donnell DE, Laveneziana P. The clinical importance of dynamic lung hyperinflation in COPD. COPD. 2006;3:219-232.

3. O'Donnell DE, Webb KA, Neder JA. Lung hyperinflation in COPD: applying physiology to clinical practice. COPD Res Pract. 2015;1:112. doi:10.1186/s40749-015-0008-8

4. Puente-Maestu L, Stringer WW. Hyperinflation and its management in COPD. Int J Chron Obstruct Pulmon Dis. 2006;1:381.

5. World Health Organization. Global Initiative for Chronic Obstructive Lung Disease, Global strategy for the diagnosis, management and prevention of chronic obstructive pulmonary disease (2019 report), 2019 [cited February 26, 2019] Available from: https://goldcopd.org/ wp-content/uploads/2018/11/GOLD-2019-v1.7-FINAL-14Nov2018WMS.pdf.

6. Buhl R, Maltais F, Abrahams R, et al. Tiotropium and olodaterol fixeddose combination versus mono-components in COPD (GOLD 2-4). Eur Respir J. 2015;45:969-979. doi:10.1183/09031936.00136014

7. Beeh KM, Westerman J, Kirsten AM, et al. The 24-h lung-function profile of once-daily tiotropium and olodaterol fixed-dose combination in chronic obstructive pulmonary disease. Pulm Pharmacol Ther. 2015;32:53-59. doi:10.1016/j.pupt.2015.04.002

8. Calverley PM, Anzueto AR, Carter K, et al. Tiotropium and olodaterol in the prevention of chronic obstructive pulmonary disease exacerbations (DYNAGITO): a double-blind, randomised, parallelgroup, active-controlled trial. Lancet Respir Med. 2018;6:337-344. doi:10.1016/S2213-2600(18)30102-4

9. O'Donnell DE, Casaburi R, Frith P, et al. Effects of combined tiotropium/olodaterol on inspiratory capacity and exercise endurance in COPD. Eur Respir J. 2017;49:1601348. doi:10.1183/ 13993003.01348-2016

10. Gelb AF, Gutierrez CA, Weisman IM, Newsom R, Taylor CF, Zamel N. Simplified detection of dynamic hyperinflation. Chest. 2004;126:1855-1860. doi:10.1378/chest.126.6.1855

11. Kawachi S, Fujimoto K. Usefulness of a newly developed spirometer to measure dynamic lung hyperinflation following incremental hyperventilation in patients with chronic obstructive pulmonary disease. Intern Med. 2018. doi:10.2169/internalmedicine.1212-18

12. Fujimoto K, Kitaguchi Y, Kanda S, Urushihata K, Hanaoka M, Kubo $\mathrm{K}$. Comparison of efficacy of long-acting bronchodilators in emphysema dominant and non-dominant COPD. Int J Chron Obstruct Pulmon Dis. 2011;6:219-227. doi:10.2147/COPD.S18461

13. Fujimoto K, Yamazaki H, Ura M, Kitaguchi Y. Efficacy of tiotropium and indacaterol monotherapy and their combination on dynamic lung hyperventilation in COPD: a random open-label crossover study. Int J Chron Obstruct Pulmon Dis. 2017;12:3195-3201. doi:10.2147/COPD.S149054

14. Mosley JF II, Smith LL, Dutton BN. Tiotropium bromide/olodaterol (Stiolto Respimat): once-daily combination therapy for the maintenance of COPD. P T. 2016;41:97.

15. Edsbäcker S, Johansson CJ. Airway selectivity: an update of pharmacokinetic factors affecting local and systemic disposition of inhaled steroids. Basic Clin Pharmacol Toxicol. 2006;98:523-536. doi:10.1111/j.1742-7843.2006.pto_355.x

16. Sasaki E, Nakamura M, Kida K, et al. Reference values for spirogram and blood gas analysis in Japanese non-smoking healthy adults. $J$ Jpn Respir Soc. 2001;39:383-399.

17. Nishida S, Kambe M, Sewake N, Takano M, Kawane H. Pulmonary function in healthy subjects and its prediction-5: pulmonary diffusing capacity in adults. Jpn J Clin Pathol. 1976;24:941-947.

18. Boren HG, Kory RC, Syner JC. The veterans administration army cooperative study of pulmonary function. Am J Med. 1966;41:96114. doi:10.1016/0002-9343(66)90008-8 
19. ATS Committee on Proficiency Standards for Clinical Pulmonary Function Laboratories. ATS statement: guidelines for the six-minute walk test. Am J Respir Crit Care Med. 2002;166:111-117. doi:10.1164/ajrccm.166.1.at1102

20. Roskell NS, Anzueto A, Hamilton A, Disse B, Becker K. Once-daily long-acting beta-agonists for chronic obstructive pulmonary disease: an indirect comparison of olodaterol and indacaterol. Int J Chron Obstruct Pulmon Dis. 2014;9:813. doi:10.2147/COPD.S60179

21. O`Donnell DE, Flüge T, Gerken F, et al. Effects of tiotropium on lung hyperinflation, dyspnoea and exercise tolerance in COPD. Eur Respir J. 2004;23:832-840.

22. Fujimoto K, Yoshiike F, Yasuo M, et al. Effects of bronchodilators on dynamic hyperinflation following hyperventilation in patients with COPD. Respirology. 2007;12:93-99. doi:10.1111/j.14401843.2006.00963.x

23. Ichinose M, Minakata Y, Motegi T, et al. Efficacy of tiotropium/olodaterol on lung volume, exercise capacity, and physical activity. Int J Chron Obstruct Pulmon Dis. 2018;13:1407. doi:10.2147/COPD.S166023

24. Singh D, Gaga M, Schmidt O, et al. Effects of tiotropium+ olodaterol versus tiotropium or placebo by COPD disease severity and previous treatment history in the OTEMTO® studies. Respir Res. 2016;17:73. doi: 10.1186/s12931-016-0387-7
25. Tashkin DP, Celli B, Decramer M, et al. Bronchodilator responsiveness in patients with COPD. Eur Respir J. 2008;31:742-750. doi: $10.1183 / 09031936.00129607$

26. Holland AE, Nici L. The return of the minimum clinically important difference for 6-minute-walk distance in chronic obstructive pulmonary disease. Am J Respir Crit Care Med. 2013;187:335-336. doi:10.1164/rccm.201212-2191ED

27. Casaburi R, Maltais F, Porszasz J, et al. Effects of tiotropium on hyperinflation and treadmill exercise tolerance in mild to moderate chronic obstructive pulmonary disease. Ann Am Thorac Soc. 2014;11:1351-1361. doi:10.1513/AnnalsATS.20 1404-1740C

28. Ferguson GT, Fležar M, Korn S, et al. Efficacy of tiotropium+ olodaterol in patients with chronic obstructive pulmonary disease by initial disease severity and treatment intensity: a post hoc analysis. $A d v$ Ther. 2015;32:523-536. doi:10.1007/s12325-0150218-0

29. Guideline for bioequivalence studies of generic products [homepage on the Internet]. Japan: Pharmaceutical and Food Safety Bureau; 2012. Available from: http://www.nihs.go.jp/drug/beguidee/Generic/GL-E_120229_BE.pdf. Accessed March 3, 2019.

\section{Publish your work in this journal}

The International Journal of COPD is an international, peer-reviewed journal of therapeutics and pharmacology focusing on concise rapid reporting of clinical studies and reviews in COPD. Special focus is given to the pathophysiological processes underlying the disease, intervention programs, patient focused education, and self management protocols. This journal is indexed on PubMed Central, MedLine and CAS. The manuscript management system is completely online and includes a very quick and fair peer-review system, which is all easy to use. Visit http://www.dovepress.com/testimonials.php to read real quotes from published authors. 